\title{
Evaluation of In vitro Phytotoxic Activity of Medicinally Important Acer pentapomicum (Maple Plant)
}

\section{Shehla Khan*, Jehan Bakht}

Institute of Biotechnology and Genetic Engineering, The University of Agriculture Peshawar, Pakistan

Submission: July 07, 2020; Published: August 18, 2020

"Corresponding author: Shehla Khan, Institute of Biotechnology and Genetic Engineering, The University of Agriculture Peshawar, Pakistan

\section{Abstract}

Over recent years new bioherbicides compounds from natural sources has gained much interest from the researcher's world widely. In this study the phytotoxicity of the crude extract and its various fractions from both the stem and leaves of Acer pentapomicum (maple plant) against Lemna minor has been studied. All the fractions except aqueous extract have exhibited highly significant phytotoxicity at different concentration when compared Paraquat as a positive control. The highest herbicidal activities of $87 \%$, was exhibited by butanol extracted samples from stem, followed by chloroform and ethyl acetate exhibiting $81 \%$ and $80 \%$ respectively. Our results confirmed that both leaves and stem extracted samples possess potent inhibitory activity against Lemna minor.

Keywords: Phytotoxic activity; Lemna minor; Acer pentapomicum (Figure 1)

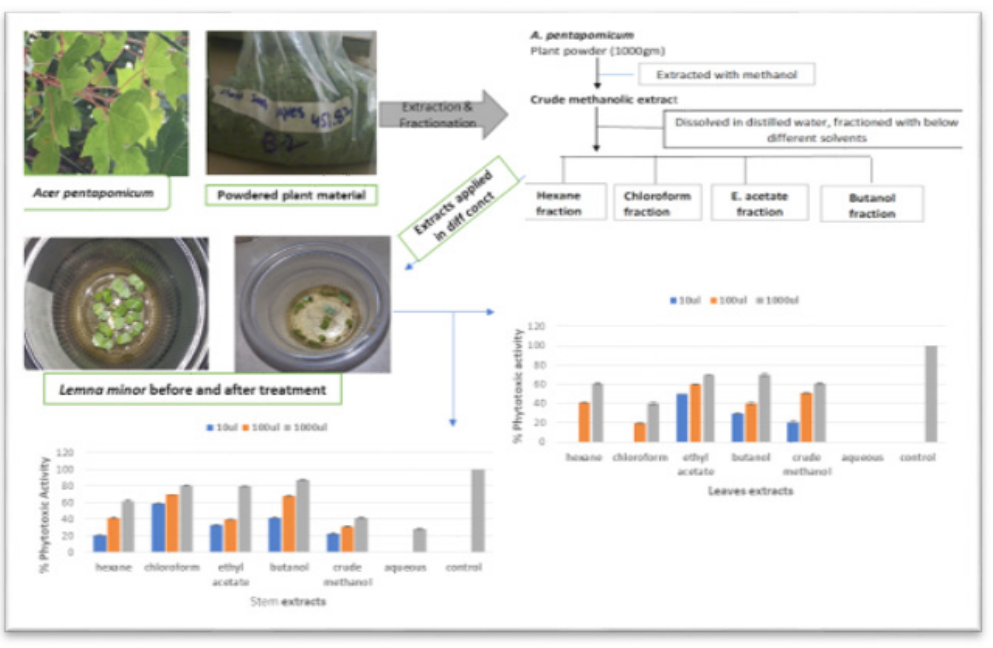

Figure 1: Graphical Abstract.

\section{Introduction}

Increasing emergence of herbicidal resistant weeds requires the discovery of new herbicides as the synthetic herbicide is becoming less effective day by day. Researchers, therefore, are trying to discover the new herbicides from the natural resources such as plant products [1-3]. These bioactive agrochemicals from the plant served to be more effective, nonhazardous, and ecofriendly [4]. The increase in interest on medicinal plants is due to the easier screening process of phytotoxic plants and the various bioactive compounds present in plant extracts that could be used as potential phytotoxic agent [5]. There are several ways in which these phytotoxic plants could be utilized to control weeds such as 
a. Planting them as cover crops with other main plants,

b. Direct application of the crude extracts,

c. Isolating and characterizing the bioactive substances and using them as a new natural and biodegradable source for herbicides development [6,7].

The genus Acer (Aceraceae), generally known as Maple family. The genus Acer (Aceraceae) is composed of 128 species, majority of these species are indigenous to Asia while some are native to

North Africa, North America, and Europe [8]. Acer pentapomicum commonly known as maple is one of the species of Aceraceae family. A. pentapomicum is a deciduous small-tree or shrub with brownish grey, flat bark. Leaves palmately 3-lobed; lobes are trilateral, the upper side of the leaves is grey-green while the lower side is pale green.

Flowers: greenish, 5-merous, smaller petals. 8-stamens present at edges of the disc. Ovary is glabrate: style connate at the surface. A pentapomicum is locally known as Tarkana and is native to Northern areas of Pakistan [9]. The plant is phenolic rich and known to possess potent medicinal properties [10]. In our current study, we investigated the phytotoxic activity of various plant extracted samples from the leaves and stems of Acer pentapomicum. To the best of our knowledge we are the first one to report the phytotoxic activity of Acer pentapomicum.

\section{Materials and Methods}

\section{Collection of plant material}

The A. pentapomicum plant was collected from the Swat valley Northern area of Pakistan, which is known for its rich flora of medicinal plants. The leaves and stems were shade dried and powdered using Anex blender grinder AG-6040.

\section{Extraction and fractionation of plant material}

For extraction of plant material, method described by [11] was followed. Briefly, about 500gm of A. pentapomicum leaves powder was soaked in methanol for 5-6 days with daily thoroughly mixing. The crude methanolic extract obtained was then filtered and concentrated through rotary evaporator. Few grams of the dried crude methanolic extracts thus obtained was kept aside and the rest was dissolved in $300 \mathrm{ml}$ distilled water for fractionation with different solvents of hexane chloroform ethyl acetate, butanol, and water. The different fraction thus obtained were filtered, concentrated, and dried using rotary evaporator. Hence, six different solvent extracted samples were obtained and used for phytotoxic activities (Figure 2).

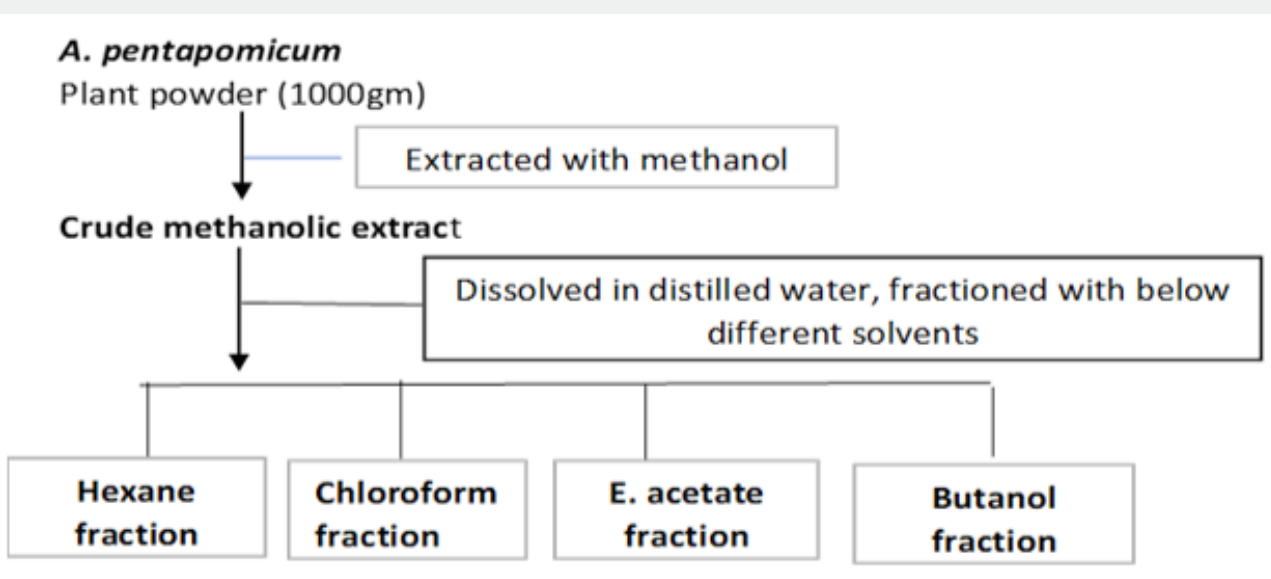

Figure 2: Flow chart of plant crude extract preparation and fractionation by various solvents.

\section{Phytotoxic activity of different plants extracted samples}

Phytotoxic activity of crude methanolic extract and its different fractions was screened against Lemna minor (weed) plants following the method of [12]. The Lemna minor plants were provided by Botany Department University of Peshawar, KPK Pakistan. Stock solutions of different solvent extracted fractions were prepared by dissolving $30 \mathrm{mg}$ of each sample in $1 \mathrm{ml}$ methanol. The test samples in the concentration of 10,100 , $1000 \mu \mathrm{g} / \mathrm{ml}$ from the stock solutions were inoculated into separate sterilized flasks. The flasks were then left for $24 \mathrm{hrs}$. so that the organic solvent get evaporated. The flasks with test samples were introduced with $20 \mathrm{ml}$ of enriched media and inoculated with
10 healthy Lemna minor plants each having a rosette of three fronds. The flask only with an enriched medium, Lemna minor plants and no tested sample served as negative control while the flask with plants and Paraquat (standard growth inhibitor) in a concentration of $0.015 \mu \mathrm{g} / \mathrm{ml}$ was used as a positive control. All the flasks were placed in a growth chamber at room temperature and for 7 days. On the eighth day, the phytotoxic activity was determined by recording the number of fronds in test sampled flasks and in control. The percent growth inhibition was calculated by the following formula described by [13].

Percent growth inhibition $(\%)=$ No. of fronds in test sample / No. of fronds in Control $x 100$ 


\section{Statistical Analysis}

Data are presented as mean value of three replicates. MSTATC software was used to carry out statistical analysis [14]. Standard deviation was calculated for each treatment [15].

\section{Results and Discussion}

In the present study we investigated the phytotoxic potential of A. pentapomicum plant (stem and leaves) extracted samples to explore its efficacy and use as a natural herbicide. The phytotoxic activity of crude methanolic extract and its different fractions from leaves of A. pentapomicum against Lemna minor is graphically depicted in Figure 3 which revealed that crude methanol, butanol and ethyl acetate extracts were equally effective against L.minor plants in inhibiting its proliferation at all concentration $(10 \mu \mathrm{l}, 100 \mu \mathrm{l}, 1000 \mu \mathrm{l}$. Butanol and ethyl acetate fractions both showed same $70 \%$ of phytotoxic potential at $1000 \mu$ l. Hexane and chloroform were effective at higher concentration. However, were found ineffective at low concentration. Our data further suggested that ethyl acetate fraction carried highest inhibitory activity against L.minor plants at all concentration. [13,16] reported similar results for different plants. Aqueous extract however, did not show any detectable inhibition against the L.minor. The order of phytotoxic efficacy for different fractions of leaves against the tested plant was found to be ethyl acetate $>$ butanol $>$ crude methanol $>$ hexane $>$ choloroform $>$ aqueous.

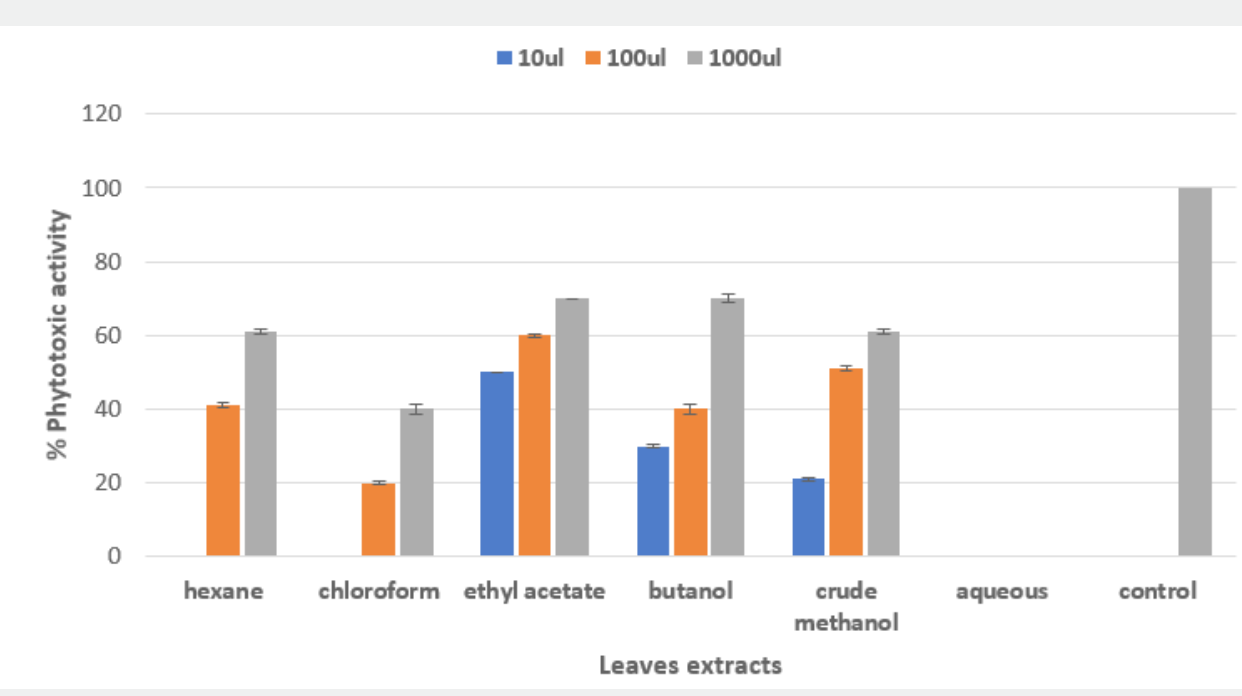

Figure 3: Phytotoxic activity of different solvent extracted samples from A. pentapomicum leaves against Lemna minor.

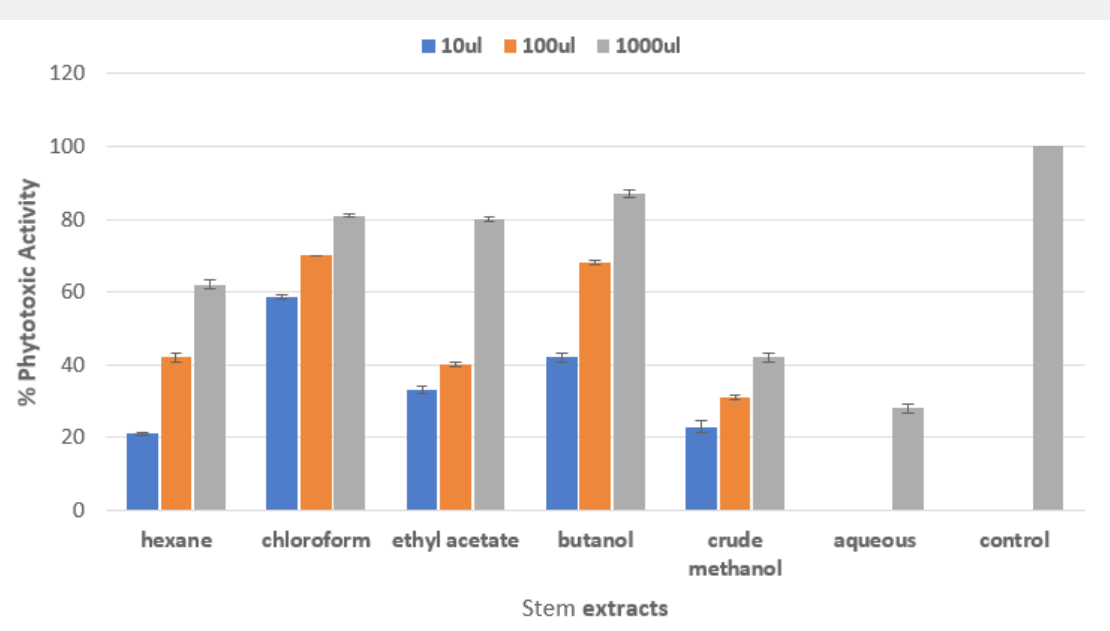

Figure 4: Phytotoxic activity of different solvent extracted samples from A. pentapomicum Stem against Lemna minor. 
Regarding the phytotoxic activity of different solvent fractions of Acer pentapomicum stem, our data clearly indicated that all the fractions except aqueous extract were effective against Lemna minor growth (Figure 4) The highest inhibitory activities of $87 \%$, $81 \%$ and $80 \%$ were exhibited by butanol, chloroform and ethyl acetate at $1000 \mu \mathrm{l}$ respectively. However, moderate herbicidal activities were recorded for hexane and crude methanolic fractions. Aqueous fraction, on the other hand, was found to be completely ineffective at lower concentration. Phytotoxic activity of different tested fractions was in the order of chloroform $>$ butanol $>$ ethyl acetate $>$ hexane $>$ crude methanol $>$ aqueous fraction [17].

\section{Conclusion}

It is the first ever reported study, and our results indicated that Acer pentapomicum plant extracts have potent phytotoxic efficacy against the tested weed and hence it might be useful as natural herbicide product.

\section{Acknowledgement}

The authors would like to thank Higher Education Commission of Pakistan for financial support.

\section{References}

1. MW Aktar, D Sengupta, A Chowdhury (2009) Impact of pesticides use in agriculture: their benefits and hazards. Interdisciplinary Toxicology 2(1): 1-12.

2. M Pell, B Stenberg, L Torstensson (1998) Potential denitrification and nitrification tests for evaluation of pesticide effects in soil. Ambio 27: 24-28.

3. PA Roger, I Simpson, R Oficial, S Ardales, R Jimenez (1994) Effects of pesticides on soil and water microflora and mesofauna in wetland ricefields: a summary of current knowledge and extrapolation to temperate environments. Austra J Experi Agricu 34(7): 1057-1068.

4. Bhowmik PC, Inderjit (2003) Challenges and opportunities in implementing allelopathy for natural weed management. Crop Protec 22: 661-671.

5. Y Fujii, M Furukawa, Y Hayakawa, K Sugawara, T Shibuya (1991) Survey of Japanese medicinal plants for the detection of allelopathic properties. Weed Research Japan 36: 36-42.
6. Y Fujii, SS Parvez, MM Parvez, Y Ohmae, O Uda (2003) Screening of 239 medicinal plant species for allelopathic activity using the sandwich method. Weed Biol Manag 3(4): 233-241.

7. SA Gilani, Y Fujii, ZK Shinwari, M Adnan, A Kikuchi, et al. (2010) Phytotoxic studies of medicinal plant species of Pakistan. Paki J Bot 42(2): 987-996.

8. Tingzhi Xu, Yousheng C, Piet CJ, Herman JO, Sung CC (2012) Acer Linnaeus. Flora of China. Missouri Botanical Garden, St. Louis, MO \& Harvard University Herbaria, Cambridge, MA.

9. Mehboob u Rahman (2012) Wild plants of Swat, Pakistan. Department of Botany, Government Jehanzeb college Swat 1: 52.

10. Shehla khan, Jehan Bakht, Muhammad Shafi (2018) Antinociceptive, antimicrobial potential and phytochemical screening of different solvent extracted samples from the stem of Acer pentapomicum. Pak J Pharm Sci 31(4): 1457-1461.

11. Bakht J, S Khan, M Shafi (2014) In vitro anti-microbial activity of Allium cepa (dry bulbs) against Gram positive and Gram-negative bacteria and fungi. Pak J Pharm Sci 27: 139-145.

12. McLaughlin JL, CL Chang, DL Smith (1991) Simple bench-top bioassays (brineshrimp and potato discs) for the discovery of anti-tumor compounds. In: Human Medicinal Agents from Plants (Eds.), pp. 112137.

13. Nisar M, SA Tariq, IK Marwat, MR Shah, IA Khan (2009) Antibacterial, antifungal, insecticidal, cytotoxicity and phytotoxicity studies on Indigofera gerardiana. Journal of Enzyme Inhibition and Medicinal Chemistry 24(1): 224-229.

14. Russel DF, Eisensmith SP (1983) MSTAT-C, Crop Soil Science Department, Michigan State University, East Lansing, ML. USA.

15. Steel RGD, JH Torrie, DA Dickey (1997) Principles and procedures of statistics. A Biometrical Approach, McGraw Hill Book Co Inc New York, USA, p. 666

16. Dastagir G, F Hussain (2013) Phytotoxic and insecticidal activity of plants of Family Zygophyllaceae and Euphorbiaceae. Sarhad Journal of Agriculture 29(1): 83-91.

17. Rehman Ullah, M Ibrar, S Shah, I Hameed (2012) Phytotoxic, cytotoxic and insecticidal activities of Calendula arvensis L. J Biotech Pharmac Res 3(6): 104-111.

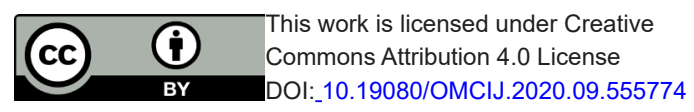

Your next submission with Juniper Publishers
will reach you the below assets
- Quality Editorial service
- Swift Peer Review
- Reprints availability
- E-prints Service
- Manuscript Podcast for convenient understanding
- Global attai nment for your research
- Manuscript accessibility in different formats
( Pdf, E-pub, Full Text, Audio)
- Unceasing customer service
Track the below URL for one-step submission
https://juniperpublishers.com/online-submission.php

